\title{
The Metabolic Profile of Tumor and Virally Infected Cells Shapes Their Microenvironment Counteracting T Cell Immunity
}

\begin{abstract}
Isabelle Magalhaes ${ }^{1 *}$, Ohad Yogev ${ }^{2}$, Jonas Mattsson ${ }^{1,3,4}$ and Anna Schurich ${ }^{5 *}$
'Department of Oncology-Pathology, Karolinska Institutet, Stockholm, Sweden, ${ }^{2}$ Division of Infection and Immunity, University College London, London, United Kingdom, ${ }^{3}$ Gloria and Seymour Epstein Chair in Cell Therapy and Transplantation, Division of Medical Oncology and Hematology, Princess Margaret Cancer Centre, Toronto, ON, Canada, ${ }^{4}$ Department of Medicine, University of Toronto, Toronto, ON, Canada, ${ }^{5}$ Department of Infectious Diseases, King's College London, London, United Kingdom
\end{abstract}

Upon activation naïve $T$ cells undergo metabolic changes to support the differentiation into subsets of effector or regulatory cells, and enable subsequent metabolic adaptations to form memory. Interfering with these metabolic alterations leads to abrogation or reprogramming of $\mathrm{T}$ cell differentiation, demonstrating the importance of these pathways in T cell development. It has long been appreciated that the conversion of a healthy cell to a cancerous cell is accompanied by metabolic changes, which support uncontrolled proliferation. Especially in solid tumors these metabolic changes significantly influence the tumor microenvironment (TME) and affect tumor infiltrating immune cells. The TME is often hypoxic and nutrient depleted, additionally tumor cells produce co-inhibitory signals, together suppressing the immune response. Interestingly, viruses can stimulate a metabolism akin to that seen in tumor cells in their host cells and even in neighboring cells (e.g., via transfer of virally modified extracellular vesicles). Thus, viruses create their own niche which favors viral persistence and propagation, while again keeping the immune response at bay. In this review we will focus on the mechanisms employed by tumor cells and viruses influencing $T$ cell metabolic regulation and the impact they have on shaping T cell fate.

Keywords: metabolism, tumor, T cell, virus, hypoxia

\section{INTRODUCTION}

In recent years the fundamental importance of energy regulation in immune cells has been appreciated and has created the research field of "Immunometabolism." Since there are excellent current reviews discussing the metabolic regulation of $\mathrm{T}$ cells in detail (1-3), we will here only give a short overview and then focus on the role of the tumor or virally infected target cell in manipulating $\mathrm{T}$ cell fate. The reader might also find Table $\mathbf{1}$ helpful, summarizing the main mechanisms discussed for a quick overview. Naïve T cells are relatively quiescent cells that have a low energetic demand. They predominantly make use of mitochondrial oxidative phosphorylation (OXPHOS). Upon antigen encounter and activation by professional antigen presenting cells, $\mathrm{T}$ cells increase the expression of nutrient transporters, especially glucose transporters 1 and 3 (GLUT1 and 3) (26) and start utilizing glycolysis even in the presence of sufficient oxygen. Glycolysis provides fast energy and biological building blocks required for cell division and effector function. Alongside, 
mitochondrial biogenesis is also activated and mitochondrial mass increased, allowing for increased respiration. Furthermore, a recent study highlights the important role of distinct mitochondrial metabolic pathways in regulating $\mathrm{T}$ cell proliferation and effector differentiation (27). Mitochondrial function is critical, and its disruption seems to be an underlying mechanism of $\mathrm{T}$ cell exhaustion (28-30). Upon the resolution of an acute insult (such as an acute viral infection) a proportion of the effector $\mathrm{T}$ cell pool differentiates into memory cells. This conversion is accompanied by the cell's metabolism refocussing on OXPHOS and fatty acid metabolism, while reducing glycolysis. Memory $\mathrm{T}$ cells have an increased mitochondrial mass and contain mitochondria with densely packed cristae linked to more efficient OXPHOS (31), poised to mount a fast recall response. In the situation where the immune response fails to deal with the insult effectively and $\mathrm{T}$ cells are subjected to persisting antigenic challenge like in cancer and chronic viral infection, effector responses become less vigorous and instead of developing into classical memory cells, formation is skewed toward exhaustion. Here we will discuss aspects of how the metabolic profile and signaling by target cells shapes their microenvironment and the impacts on $\mathrm{T}$ cell function, differentiation and fate decision.

\section{THE INCREASED GLYCOLYSIS IN CANCER CELLS IMPACTS ON T CELLS}

Reprogramming of energy metabolism has been recognized as one of the hallmarks of cancer cells (32). It is well established that cancer cells have increased glucose uptake, which is fermented to lactate even in the presence of oxygen, a process known as aerobic glycolysis (or Warburg effect). Of note, glucose can also be further metabolized through the mitochondrial tricarbolyxic acid (TCA) cycle in tumors (33).

Glucose is an important source of carbon for the production of amino acids, nucleotides, and fatty acids. Oncogenic mutations of the phosphatase and tensin homolog (PTEN) and the phosphoinositide 3-kinase (PI3K) pathway lead to the reprogramming of glucose metabolism and increased glucose uptake via stimulation of glucose transporters in cancer cells [recently reviewed by Marbaniang et al. (34)]. Increased transcription of glycolysis genes in KRAS mutated colorectal cancer cell lines (35) is another example of the impact of oncogenic mutations on the cellular metabolic state. Mutations in the tumor suppressor gene p53 was shown to play a role in glucose metabolism, and interestingly also in mitochondrial activity and lipid metabolism (36).

The sustained consumption of glucose by tumor cells eventually leads to a decrease of glucose levels in the TME. Competition for glucose between tumor and $\mathrm{T}$ cells has been shown to decrease IFN- $\gamma$ production by CD8 $+\mathrm{T}$ cells and to limit $\mathrm{T}$ cell antitumor functions $(4,5)$. Conversion of glycolysis intermediates by the pentose phosphate pathway generates $\mathrm{NADPH}$ (that can serve as an electron acceptor), which is needed for tumor cells to scavenge reactive oxygen species (ROS)
TABLE 1 | Table summarizing metabolic pathways and their role in tumors/TME and viral infection.

\begin{tabular}{|c|c|c|}
\hline Mechanism & Tumor & Virus \\
\hline Glycolysis & $\begin{array}{l}\text { (i) Glucose depleted TME } \\
\text { (ii) Inhibition of effector T } \\
\text { cells }(4,5)\end{array}$ & $\begin{array}{l}\text { Stimulation of increased } \\
\text { glycolysis in host cell for viral } \\
\text { production and in } \\
\text { neighboring cells via } \\
\text { exosomes e.g., HTLV, HIV, } \\
\text { KSHV, EBV }(6,7)\end{array}$ \\
\hline $\begin{array}{l}\text { Hypoxia/ } \\
\text { pseudohypoxia }\end{array}$ & $\begin{array}{l}\text { Stabilization of HIF1- } \alpha \text { : } \\
\text { (i) Enhances glycolysis and } \\
\text { acidosis of TME (8) } \\
\text { (ii) Expression of } \\
\text { ectoenzymes } \\
\text { CD39/CD73 increasing } \\
\text { extracellular adenosine } \\
\text { levels (9) } \\
\text { (iii) Upregulation of } \\
\text { PD-L1 (10) }\end{array}$ & $\begin{array}{l}\text { Stabilization of HIF1- } \alpha \\
\text { mimicking the effect of } \\
\text { hypoxia (termed: } \\
\text { pseudohypoxia) } \\
\text { e.g., KSHV, EBV, HCV, } \\
\text { HCMV, HPV }(11,12)\end{array}$ \\
\hline Lactate production & $\begin{array}{l}\text { (i) Acidification of TME } \\
\text { (ii) Inhibition of effector T } \\
\text { cells }(13,14) \\
\text { (iii) Inhibition of CD4+ Th1 T } \\
\text { cells (15) } \\
\text { (iv) Promotion of Treg (15) } \\
\text { (v) Induction of regulatory } \\
\text { macrophages (16) } \\
\text { (vi) Upregulation of } \\
\text { PD-L1 (17) }\end{array}$ & $\begin{array}{l}\text { Lactate secretion from } \\
\text { (i) infected cells and } \\
\text { (ii) neighboring cells } \\
\text { stimulated by virally } \\
\text { infected cells, creates } \\
\text { microenvironment } \\
\text { supporting viral } \\
\text { propagation (e.g., } \\
\mathrm{KSHV}) \text { ? }(4,18)\end{array}$ \\
\hline $\begin{array}{l}\text { Amino acid } \\
\text { depletion }\end{array}$ & $\begin{array}{l}\text { (i) Increased glutaminolysis } \\
\text { leads to glutamine } \\
\text { depletion in TME (19) } \\
\text { (ii) Expression of } \\
\text { indoleamine } \\
\text { 2,3-dioxygenase leads to } \\
\text { depletion of } \\
\text { tryptophan (20) } \\
\text { (iii) Recruitment/induction of } \\
\text { MDSC, which can } \\
\text { deplete the essential } \\
\text { amino acids cysteine } \\
\text { and arginine } \\
\text { Inhibition of effector T cells } \\
\text { Induction of Treg (23) }\end{array}$ & $\begin{array}{l}\text { Recruitment of MDSC e.g., } \\
\text { to HBV infected liver (21) } \\
\text { Inhibition of amino acid } \\
\text { uptake mediated by HIV } \\
\text { Vpu protein (22) }\end{array}$ \\
\hline Lipid metabolism & $\begin{array}{l}\text { Induction of increased } \\
\text { release of fatty acids by } \\
\text { adipocytes to fuel tumor (24) }\end{array}$ & $\begin{array}{l}\text { Induction/modulation of } \\
\text { fatty acid production e.g., } \\
\mathrm{CMV}, \mathrm{KSHV}, \mathrm{HCV}, \mathrm{Zika} \text {, } \\
\text { Dengue (25) }\end{array}$ \\
\hline
\end{tabular}

and maintain redox homeostasis. ROS produced by tumor cells participate in the oxidative stress $\mathrm{T}$ cells encounter in the TME, and interestingly, Tregs are more resistant than conventional CD4+ T cells to oxidative stress-induced cell death (37).

\section{THE INFLUENCE OF HYPOXIA ON T CELL FUNCTION}

Reduced blood flow in some tumor areas results in low oxygen levels (hypoxia) and acidification as discussed below and shown in Figure 1. Hypoxia leads to the stabilization of the transcription factor hypoxia-inducible factor $1-\alpha(\mathrm{HIF} 1-\alpha)$. HIF1- $\alpha$ in cancer 


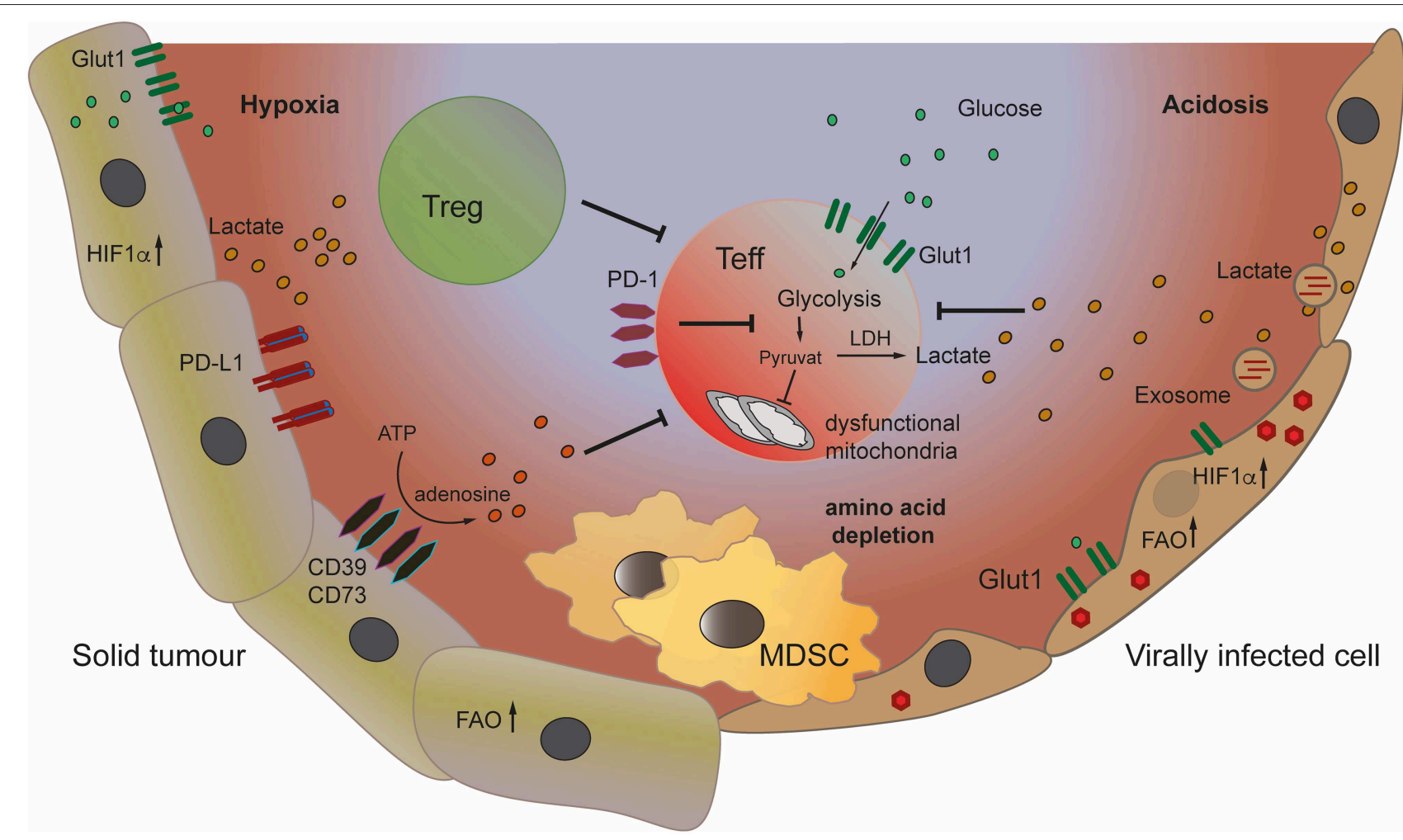

FIGURE 1 | Metabolic changes in tumor and virally infected cells can create a suppressive microenvironment leading to inhibition of effector T cells. The architecture of the tumor microenvironment (TME) can create hypoxic areas, leading to stabilization of HIF1- $\alpha$ in tumor cells and increase of glycolysis, depleting the TME of glucose. Increased glycolysis and production of lactate leads to acidification of the TME. Lactate inhibits effector T cells, while promoting Treg. Tumor cells convert ATP to immune suppressive adenosine by expressing the ectoenzymes CD39/CD73. The recruitment and induction of myeloid derived suppressor cells (MDSC) to the TME and to virally infected organs increases immune inhibition. Viruses also induce glycolysis and lactate production in infected and neighboring cells through the transfer of viral signaling molecules to their target cells via exosomes.

cells promotes glucose uptake by upregulation of GLUT1, GLUT3, and increased expression of glycolytic enzymes further promoting glycolysis and acidosis (8). In an elegant study Walton et al. have demonstrated that high acidity in the context of hypoxia results in inhibition of mTOR signaling in $\mathrm{T}$ cells and induction of $\mathrm{T}$ cell anergy. mTOR is a key sensor of nutrients and a major regulator of cellular metabolism and effector $\mathrm{T}$ cell function (38). Earlier studies had demonstrated that mTOR inhibition in the presence of TCR triggering drives T cell anergy (39), while promoting Treg development (40). Taken together these mechanisms might conceivably play a role in the tumor microenvironment in vivo, with both $\mathrm{T}$ effector cell inhibition and increased Treg numbers detrimental to tumor control. Various viruses (e.g., HCV and human papillomaviruses) have also been shown to manipulate the host cell's metabolism by promoting through different mechanisms HIF1- $\alpha$ stability and activity $(11,12)$ in the absence of hypoxia leading to subsequent increased glycolysis. In a recent report, influenza A (H1N1) virus led to proteasome inhibition and in turn stabilization of HIF1- $\alpha$ in normoxic conditions, however the impact on viral replication remains to be determined (41).

Apart from driving increased glycolysis HIF1- $\alpha$ induces expression of the ectoenzyme CD73 (9) and the expression by cancer cells and Tregs of the tandem ectoenzymes CD39/CD73 which generate extracellular adenosine from the degradation of extracellular ATP. The binding of adenosine to the 2A2adenosine receptor (A2AR) expressed by many immune cells including T cells, inhibits anti-tumor T cells (42). Finally, HIF1- $\alpha$ is also involved in the upregulation of PD-L1 by tumor cells (10). Interestingly, a deregulated oxidative metabolism in tumors and the associated hypoxia in the TME, correlated with resistance to PD-1 treatment (43).

A recent publication shows that hypoxia and glucose deprivation lead to down-regulation of MHC class I molecules on tumor cells facilitating immune escape. This finding was accompanied by tumor cells losing their sensitivity to IFN- $\gamma$ mediated induction of MHC upregulation (44). Consequently, tumor cells evade killing by activated IFN- $\gamma$ producing $\mathrm{T}$ cells creating another hurdle for $\mathrm{T}$ cell therapies.

\section{TUMOR CELLS PRODUCE LACTATE THAT PROMOTES IMMUNE SUPPRESSION}

In addition, the lactate secreted by glycolytic tumor cells into the TME adversely impacts on effector T cells. Lactate inhibits 
CD8 + T cell proliferation, cytokine (IL-2 and IFN- $\gamma$ ) production, and cytotoxicity $(13,14)$, but also induces $\mathrm{T}$ cell apoptosis $(45)$. These effects on activated CD8 $+\mathrm{T}$ cells by increased lactate levels are mediated through inhibition of NFAT upregulation and inhibition of phosphorylation of p38 MAP kinase and JNK $(14,45)$. A recent report demonstrated that exogenous lactate can reduce the frequency of Th1 CD $4+\mathrm{T}$ cells and their IFN$\gamma$ production, while increasing the expression of FoxP3 and the frequency of regulatory CD4 $+\mathrm{T}$ cells (Tregs) (15). Expression of cell surface GLUT1 is lower in Tregs as compared to other CD4+ T cell subsets, and Tregs appear not to rely on glycolysis but rather lipid oxidation and OXPHOS (46). FoxP3 was shown to play a role in inducing resistance to the suppressive effects of lactate by mediating distinct metabolic adaptation in Tregs (18). The accumulation of lactate in the TME leads to TME acidification known to decrease $\mathrm{T}$ cell proliferative capacity and inducing anergy (47) (Figure 1). Interestingly, expression of the lactate receptor GPR81 by macrophages was shown to play a role in inducing immune regulatory genes and regulating inflammation (16).

Lactate was also shown to upregulate programmed cell death ligand-1 (PD-L1) expression in lung cancer cells (17). Interestingly, PD-L1 blockade on tumor cells inhibited their mTOR kinase activity and decreased the expression of glycolytic enzymes (4), which might contribute to the success of anti-PD-L1 checkpoint blockade.

Finally, the increased concentration of lactate in the TME seems to be advantageous to some tumors, as lactate can be converted to pyruvate to fuel the TCA cycle. Glycolytic tumor cells can therefore produce the fuel for neighboring cells in heterogenous tumors (48), while at the same time suppressing the immune response.

\section{TUMOR CELLS DO NOT SOLELY RELY ON GLUCOSE AS A SOURCE OF ENERGY BUT UTILIZE AMINO ACIDS LEAVING THE TME DEPLETED}

TCA activity can be replenished by mitochondrial metabolism of various amino acids such as alanine, cysteine, leucine, and fatty acids (33). Recent data shows that at least some tumors depend on the non-essential amino acid glutamine (in humans, the most abundant amino acid in the circulation), as a source of nitrogen needed for nucleotide biosynthesis, and of carbon to fuel the TCA cycle (49). Metanalysis of studies assessing the metabolic profile in patients with cancer have revealed that in addition to the expected increase in lactate in tumor tissues, other metabolic changes can be identified $(50,51)$. Glutamate and kynurenine were the two most frequently elevated metabolites when 343 pairs of tumor/normal samples were compared.

Glutamine metabolism is upregulated by many oncogenic mutations (52). The MYC oncogene is one of the most frequently amplified genes in human tumors. MYC upregulates glutamine transporters, and MYC-transformed cells are dependent on glutamine metabolism (19). This can lead to reduced levels of glutamine in the TME, compared to normal tissues, resulting in limited availability for $\mathrm{T}$ cells. In order to sustain the energetic demands of cell proliferation and differentiation following $\mathrm{T}$ cells activation, $\mathrm{T}$ cells upregulate glutamine uptake, and enzymes for glutamine metabolism. Interestingly, extracellular glutamine deprivation and subsequent decreased intracellular pool of the glutamine-derived $\alpha$-ketoglutarate promotes a shift in murine CD4+ T cells toward Treg differentiation (53). This was supported by data using human $\mathrm{T}$ cells where inhibition of glutaminolysis (conversion of glutamine into TCA cycle metabolites) promoted Treg differentiation (54).

Competition for glutamine may therefore represent an additional mechanism of immunosuppression in the TME.

Furthermore, many tumors constitutively express indoleamine 2,3-dioxygenase (IDO) which catabolizes the essential amino acid tryptophan depleting it from the TME inhibiting $\mathrm{T}$ cell proliferation (20). Depletion of tryptophan suppresses CD8+ effector $\mathrm{T}$ cell proliferation but again promotes Treg differentiation via activation of the GCN2 kinase (55). Tryptophan metabolism also releases the immunosuppressive catabolite kynurenine that activates the aryl hydrocarbon receptor which also promotes Treg differentiation (56). IDO inhibitors have been tested in clinical trials, but responses were overall disappointing either as single agents, or in combination with anti-PD1 therapy leading to a halt of some combination therapy phase III trials (57).

Tumors are well known to induce and attract myeloid derived suppressor cells (MDSC), which crucially can suppress both innate and adaptive immune responses (Figure 1). One mechanism being nutrient depletion by the sequestration of cysteine and the production of arginase-1, an enzyme leading to the break down of arginine, both amino acids being essential for $\mathrm{T}$ cells. In contrast to other cells $\mathrm{T}$ cells cannot convert the oxidized precursor cystine to the reduced amino acid cysteine and are dependent on extracellular levels (23). The depletion of arginine which has been demonstrated to contribute to suppression of $\mathrm{T}$ cell responses in cancer (58) is also operative in chronic viral infection. The HIV protein $\mathrm{Vpu}$ antagonizes amino acid uptake into CD4+ T cells (22), while in chronic hepatitis B virus (HBV) increased numbers of MDSC found in the infected liver correlate with low levels of arginine (21). As a consequence of the above combined mechanisms T cells in the TME and in chronic viral infections can find themselves depleted of essential amino acids, leaving them little ability to function effectively.

\section{THE ROLE OF LIPID METABOLISM IN THE REGULATION OF T CELL RESPONSES}

An enhanced lipid metabolism is crucially required for the synthesis of cell membranes in blasting and proliferating $\mathrm{T}$ cells (59) and highly organized lipid rafts in the membrane of effector $\mathrm{T}$ cells which enable the organization of the immunological synapse (12). A perturbation of the cholesterol and fatty acid homeostasis leads to a reduction in effector T cells. Furthermore, the development of $\mathrm{T}$ cell memory has been shown to be dependent on increased mitochondrial fatty acid oxidation $(60,61)$. Like proliferating $\mathrm{T}$ cells, proliferating cancer cells 
require fatty acids for the synthesis of membranes and other molecules. Many tumor cells acquire fatty acids through de novo synthesis, however some ovarian, prostate and breast cancers rely on the uptake of exogenous fatty acids (62). Tumor cells have been shown to communicate with adipocytes to enhance provision of fatty acids (24), establishing a link between obesity and increased risk of cancer. Viruses likewise manipulate their host cell's lipid metabolism, for example human cytomegalovirus (CMV) induces an increase in fatty acid production to synthesize lipids for incorporation into the viral envelope (63). Hepatocytes infected by Hepatitis $C$ virus (HCV) are forced to increase lipogenesis and gluconeogenesis to support viral particle production via sophisticated mechanisms involving viral proteins and interference with host miRNAs $(64,65)$. Since hepatocytes are vital in regulating systemic glucose and lipid homeostasis these manipulations by $\mathrm{HCV}$ lead to a significantly increased risk for patients to develop metabolic disorders. Pathogenic Flaviviruses, such as Zika and Dengue virus also rely on their host's lipid metabolism to complete their life cycle and thus interfere with this pathway to remodel intracellular membranes to allow virion biogenesis (25).

The importance of lipid metabolism in both cancer and viral infection make these pathways interesting candidates for therapeutic intervention.

\section{TUMORS, TME AND T CELLS ARE HETEROGENOUS}

One should keep in mind that tumor cells are proliferating, rapidly evolving cells, and metabolic changes are very heterogenous across different cancers, between patients with the same type of cancer, and within the same patient since spatial and temporal tumor cell heterogeneity also occur (66). In addition to intrinsic tumor cell differences, the heterogeneity of the tumor microenvironment (including oxygen levels/perfusion levels) influences the metabolic changes in tumor cells, which in turn as well shows heterogeneity. Tumor metabolomic analysis provides important information, however more efforts for instance in standardization of sampling, data analysis, choice of sample (cell lines, tissues, or blood), to ensure that only cancer specific changes are detected, are needed. These caveats are also true for the study of many chronic viral infections, especially where culture models are hard to establish and/or in vivo studies are limited to humanized models or primates where humans are the exclusive natural host of a virus as in HIV, HBV, HCV, and EBV.

As discussed above, metabolic suppression in the TME is important in inhibiting effector T cells and many solid tumors are devoid of much $\mathrm{T}$ cell infiltrate. Since $\mathrm{T}$ cell memory formation is equally dependent on metabolic programs, this can also be inhibited and skewed toward $\mathrm{T}$ cell deletion or dysfunction. Indeed, T cell exhaustion or Treg development occur in the TME instead of classical memory differentiation. It could be argued that exhaustion is a distinct type of memory, since exhausted $\mathrm{T}$ cells can be long lived, do retain limited effector functions and exert control over persistent viral infections (67-69).
Thus, anti-viral CD8 $+\mathrm{T}$ cells with exhausted phenotype(PD1 intermediate/high, low IFN- $\gamma$ /effector cytokine production) can for example maintain a low viral load in patients with untreated chronic HBV (70). Furthermore exhausted T cells can be reinvigorated by stimulation with cytokines such as IL-12 (71) and are targeted in immune checkpoint inhibitor therapy (69).

\section{VIRUSES MANIPULATE THE METABOLISM OF BOTH THEIR HOST CELL AND CELLS IN THEIR MICROENVIRONMENT}

Viruses acquire both the energy and the building blocks needed to synthesize progeny virions from their host. For this reason, it is not surprising that many viruses manipulate their host cell metabolic pathways and associated signaling cascades [reviewed in $(6,7)]$. Interestingly, many of these metabolic changes mimic those found in cancer. This suggests that in the case of oncogenic viruses, these metabolic alterations also contribute to cellular transformation. An example of shared metabolic alteration between viruses and cancer is the induction of the Warburg effect. Similar to many cancer types, different viruses were shown to shift glucose metabolism and redirect the glycolysis end product, pyruvate, away from mitochondrial OXPHOS. Interestingly different viruses developed diverse mechanisms to manipulate glucose metabolism in their host cells. Moreover, increased glycolysis and reduced OXPHOS were shown to support both viral replication and latency, by activating biosynthetic pathways supporting viral propagation.

In the last decade, there is accumulating evidence that viruses not only manipulate the infected cells but also communicate and manipulate other cells in their microenvironment. One method viruses use for this is manipulation of extracellular vesicle (EV) secretion from the host cell (Figure 1). An increasing number of viruses has been shown to manipulate EV-secretion and cargo(72-84).

The field of EV has been extensively studied in the last years, mainly in cancer. Tumor-derived EVs were shown to have a dramatic effect on tumor growth and metastasis [reviewed in (85-87)]. Interestingly, it was shown that both cancer cells and viruses use EV to alter the metabolism of cells in their microenvironment. A fascinating example of this phenomenon comes from the two oncogenic gammaherpesviruses Epstein Barr Virus (EBV) and Kaposi's sarcoma herpesvirus (KSHV). Both viruses establish latency quickly after primary infection. Though during latency, these viruses express only a small subset of their genome, both viruses were shown to have a complex effect on their host metabolism (88). KSHV was shown to shift glucose metabolism from mitochondrial OXPHOS to aerobic glycolysis and to induce fatty acid synthesis and glutaminolysis (89-94). One of the driving forces for these metabolic alterations is the virally encoded microRNAs, which are thought to downregulate different genes which are involved in the regulation of OXPHOS and by that shift cells to more glycolytic metabolism (94). Importantly it was shown that these microRNAs are also transferred from infected cells to noninfected cells in the microenvironment using EVs (95-97) and 
that the viral microRNAs are active in these cells to induce similar metabolic phenotype (97) Similar to KSHV, EBV was also shown to alter its host cell metabolism (98). Specifically, the latent protein LMP1 was shown to shift host cell metabolism from OXPHOS to aerobic glycolysis $(98,99)$ by inducing expression of multiple genes, such as GLUT1. In EBV-induced carcinomas this increased glycolysis promotes MDSC expansion (100) leading to tumor immunosuppression as discussed. Additionally, LMP1, which is expressed in around $30 \%$ of EBV-driven Hodgkin Lymphomas, is also involved in stimulating regulatory $\mathrm{T}$ cell responses (101). LMP1 can be transferred in EV secreted from infected cells and thus manipulate EV-recipient cells (2, $102,103)$. This suggests that similarly to KSHV, EBV can use EV to manipulate neighboring cells and thereby modulate its microenvironment.

Why do viruses alter their host's metabolism? One clear advantage is the activation of biosynthetic pathways to support viral replication. Redirecting pyruvate away from mitochondria and reducing OXPHOS can free different carbon molecules for the synthesis of nucleotides, amino acids and lipids or for protein glycosylation. Permissiveness of CD4+ T cells to HIV has been shown to be strongly influenced by the metabolic activation status of the $\mathrm{T}$ cells. CD4 $\mathrm{T}$ cells with high rates of OXPHOS and glutaminolysis where the most susceptible $(104,105)$. Indeed, HIV infection could be significantly reduced by blocking glutaminolysis (105). In the case of latent viruses, the advantage of altering their host cell's metabolism is less obvious. Since during latency, there is a minimal expression of viral proteins, these viruses are completely dependent on cellular replication to maintain and replicate their genome. Adopting a "cancer-like" metabolism might support uncontrolled cell division, which results in maintenance and amplification of the viral genome.

Altering the metabolic state of cells in the microenvironment might suggest other advantages for infected cells. For example, in KSHV infection, it was shown that altering the metabolism of non-infected cells leads to the secretion of high-energy metabolites. These metabolites are being taken up by infected cells supporting their growth. Therefore, it is suggested that viruses can use EVs to create a specific niche which supports infected host cell growth (97).

Moreover, altering the metabolic phenotype of the niche could also allow viruses to escape the immune system. Since, $\mathrm{T}$ cells as part of their differentiation and activation need to undergo dramatic reprogramming of their cellular metabolism $(3,106)$ a low glucose high lactate microenvironment restricts $\mathrm{T}$ cells, dampening their effector function $(4,18)$. This raises the intriguing hypothesis that by manipulating their host cell's metabolism viruses attenuate $\mathrm{T}$ cell function by creating a suppressive microenvironment.

\section{OUTLOOK AND THERAPEUTIC IMPLICATIONS}

A better understanding of tumor metabolism is obviously important in order to target tumor cells as well as to counteract their immunosuppressive impact on anti-tumor $\mathrm{T}$ cell responses. As described below different strategies are therefore being explored. One approach consists in the intratumor delivery by nanoparticles of RNA interference that silences lactate dehydrogenase A (LDHA) (107). The observation in preclinical models that the effect of anti-PD1 treatment in a model of melanoma, was improved in mice with $\mathrm{LDH}-\mathrm{A}$ deficient tumors (108), and that, the deletion of LDHA in myeloid cells was shown to induce $\mathrm{T}$ cell antitumor immunity against lung carcinoma (109), further validates the targeting of LDHA. Expression of catalase by chimeric antigen receptor (CAR) T cells improved the protection of CAR T cells against oxidative stress induced in part by ROS in the TME (110). A recent report showed that acetate could be used as an alternative carbone source and rescue the functions (e.g., IFN- $\gamma$ production) of exhausted tumor infiltrating $\mathrm{T}$ cells, and glucose-restricted CD8+ T cells (111).

Autophagy is a catabolic process that allows cell survival and maintenance of cell metabolism in face of stressful conditions such as nutrient starvation. In tumor cells, autophagy appears to play different roles by promoting tumor suppression but also tumor initiation (112). A better understanding of autophagy in tumors could therefore potentially be exploited to develop novel anticancer treatments. Note that in the context of viral infections, autophagy can again play a dual role by promoting or limiting viral replication (113).

Despite viruses amending the immune response, as discussed above, anti-viral responses often successfully eliminate the infecting agents or keep them life-long under control as evidenced by the rare occurrence of CMV or EBV-mediated disease in healthy individuals despite up to $90 \%$ of the human population being persistently infected (12). This has led to the interesting idea of repurposing anti-viral $\mathrm{T}$ cells against (114). In a recent study Rosato et al. demonstrated that anti-viral $\mathrm{T}$ cells can target tumors when these were loaded with exogenous viral peptide. This strategy was made even more efficient when combined with check-point blockade (114) potentially opening up new therapeutic avenues. It remains to be determined if such a strategy impacts on anti-viral control. An important question will be whether utilizing anti-viral $\mathrm{T}$ cells could over time lead to their exhaustion and/or reprogramming into Treg in the suppressive TME. Thus, the choice of viral peptide targets and combination with other strategies will be critical; especially considering that a persistent common virus such as EBV is oncogenic if uncontrolled (115).

Altering cell metabolism is one of the hallmarks of cancer. However, it is becoming clear that this effect is not limited to the tumor cells, and as part of tumor development, the metabolic phenotype of the TME is also dramatically changed. Additionally, viruses can mimic this phenotype, affecting the metabolism of both their host cells and cells in their microenvironment. Despite considerable advances, we still have some way to go in understanding how these metabolic alterations affect $\mathrm{T}$ cell response and how they could successfully be used to target cancer and chronic viral infection. However, it is clear that 
the metabolic profiling of antigen specific $T$ cells and their target cells should now be part of the development of new therapeutic strategies.

\section{AUTHOR CONTRIBUTIONS}

All authors have contributed to writing the article, and have read the manuscript.

\section{REFERENCES}

1. O'Sullivan D. The metabolic spectrum of memory T cells. Immunol Cell Biol. (2019) 97:636-46. doi: 10.1111/imcb.12274

2. Nanbo A, Kawanishi E, Yoshida R, Yoshiyama H. Exosomes derived from Epstein-Barr virus-infected cells are internalized via caveola-dependent endocytosis and promote phenotypic modulation in target cells. J Virol. (2013) 87:10334-47. doi: 10.1128/JVI.01310-13

3. Ganeshan K, Chawla A. Metabolic regulation of immune responses. Annu Rev Immunol. (2014) 32:609-34. doi: 10.1146/annurev-immunol-032713-120236

4. Chang CH, Qiu J, O’Sullivan D, Buck MD, Noguchi T, Curtis JD, et al. Metabolic competition in the tumor microenvironment is a driver of cancer progression. Cell. (2015) 162:1229-41. doi: 10.1016/j.cell.2015.08.016

5. Ho PC, Bihuniak JD, Macintyre AN, Staron M, Liu X, Amezquita R, et al. Phosphoenolpyruvate is a metabolic checkpoint of anti-tumor $\mathrm{T}$ cell responses. Cell. (2015) 162:1217-28. doi: 10.1016/j.cell.2015.08.012

6. Levy P, Bartosch B. Metabolic reprogramming: a hallmark of viral oncogenesis. Oncogene. (2016) 35:4155-64. doi: 10.1038/onc.2015.479

7. Mesquita I, Estaquier J. Viral manipulation of the host metabolic network. Exp Suppl. (2018) 109:377-401. doi: 10.1007/978-3-319-74932-7_10

8. Schurich A, Magalhaes I, Mattsson J. Metabolic regulation of CAR T cell function by the hypoxic microenvironment in solid tumors. Immunotherapy. (2019) 11:335-45. doi: 10.2217/imt-2018-0141

9. Sitkovsky MV, Hatfield S, Abbott R, Belikoff B, Lukashev D, Ohta A. Hostile, hypoxia-A2-adenosinergic tumor biology as the next barrier to overcome for tumor immunologists. Cancer Immunol Res. (2014) 2:598-605. doi: 10.1158/2326-6066.CIR-14-0075

10. Barsoum IB, Smallwood CA, Siemens DR, Graham CH. A mechanism of hypoxia-mediated escape from adaptive immunity in cancer cells. Cancer Res. (2014) 74:665-74. doi: 10.1158/0008-5472.CAN-13-0992

11. Santos SAD, Andrade DRJ. HIF-1alpha and infectious diseases: a new frontier for the development of new therapies. Rev Inst Med Trop São Paulo. (2017) 59:e92. doi: 10.1590/s1678-9946201759092

12. Pallett LJ, Schmidt N, Schurich A. T cell metabolism in chronic viral infection. Clin Exp Immunol. (2019) 197:143-52. doi: 10.1111/cei.13308

13. Fischer K, Hoffmann P, Voelkl S, Meidenbauer N, Ammer J, Edinger M, et al. Inhibitory effect of tumor cell-derived lactic acid on human T cells. Blood. (2007) 109:3812-9. doi: 10.1182/blood-2006-07-035972

14. Mendler AN, Hu B, Prinz PU, Kreutz M, Gottfried E, Noessner E. Tumor lactic acidosis suppresses CTL function by inhibition of p38 and JNK/c-Jun activation. Int J Cancer. (2012) 131:633-40. doi: 10.1002/ijc.26410

15. Comito G, Iscaro A, Bacci M, Morandi A, Ippolito L, Parri M, et al. Lactate modulates CD4(+) T-cell polarization and induces an immunosuppressive environment, which sustains prostate carcinoma progression via TLR8/miR21 axis. Oncogene. (2019) 38:3681-95. doi: 10.1038/s41388-019-0688-7

16. Ranganathan P, Shanmugam A, Swafford D, Suryawanshi A, Bhattacharjee P, Hussein MS, et al. GPR81, a cell-surface receptor for lactate, regulates intestinal homeostasis and protects mice from experimental colitis. $J$ Immunol. (2018) 200:1781-9. doi: 10.4049/jimmunol.1700604

17. Feng J, Yang H, Zhang Y, Wei H, Zhu Z, Zhu B, et al. Tumor cellderived lactate induces TAZ-dependent upregulation of PD-L1 through GPR81 in human lung cancer cells. Oncogene. (2017) 36:5829-39. doi: 10.1038/onc.2017.188

\section{FUNDING}

IM was supported by grants from Cancerfonden (190002 FE), the Dr. Åke Olsson Foundation (2019-00386), Svenska Läkaresällskapets (SLS-783531), and Clas Groschinskys Minnesfond (M 18224). JM was supported by grants from Cancerfonden (CAN2016/747), Radiumhemmet (181201), and the Mix private donation.

18. Angelin A, Gil-de-Gomez L, Dahiya S, Jiao J, Guo L, Levine MH, et al. Foxp3 reprograms $\mathrm{T}$ cell metabolism to function in lowglucose, high-lactate environments. Cell Metab. (2017) 25:1282-93 e1287. doi: 10.1016/j.cmet.2016.12.018

19. Wise DR, DeBerardinis RJ, Mancuso A, Sayed N, Zhang XY, Pfeiffer HK, et al. Myc regulates a transcriptional program that stimulates mitochondrial glutaminolysis and leads to glutamine addiction. Proc Natl Acad Sci USA. (2008) 105:18782-7. doi: 10.1073/pnas.0810199105

20. Munn DH, Shafizadeh E, Attwood JT, Bondarev I, Pashine A, Mellor AL. Inhibition of $\mathrm{T}$ cell proliferation by macrophage tryptophan catabolism. $J$ Exp Med. (1999) 189:1363-72. doi: 10.1084/jem.189.9.1363

21. Pallett LJ, Gill US, Quaglia A, Sinclair LV, Jover-Cobos M, Schurich A, et al. Metabolic regulation of hepatitis B immunopathology by myeloid-derived suppressor cells. Nat Med. (2015) 21:591-600. doi: 10.1038/nm.3856

22. Matheson NJ, Sumner J, Wals K, Rapiteanu R, Weekes MP, Vigan R, et al. Cell surface proteomic map of HIV infection reveals antagonism of amino acid metabolism by Vpu and Nef. Cell Host Microbe. (2015) 18:409-23. doi: 10.1016/j.chom.2015.09.003

23. Srivastava MK, Sinha P, Clements VK, Rodriguez P, Ostrand-Rosenberg S. Myeloid-derived suppressor cells inhibit T-cell activation by depleting cystine and cysteine. Cancer Res. (2010) 70:68-77. doi: 10.1158/0008-5472.CAN-0 9-2587

24. Nieman KM, Kenny HA, Penicka CV, Ladanyi A, Buell-Gutbrod R, Zillhardt $\mathrm{MR}$, et al. Adipocytes promote ovarian cancer metastasis and provide energy for rapid tumor growth. Nat Med. (2011) 17:1498-503. doi: 10.1038/nm.2492

25. Martin-Acebes MA, Jimenez de Oya N, Saiz JC. Lipid metabolism as a source of druggable targets for antiviral discovery against zika and other flaviviruses. Pharmaceuticals. (2019) 12:E97. doi: 10.3390/ph12020097

26. Hukelmann JL, Anderson KE, Sinclair LV, Grzes KM, Murillo AB, Hawkins $\mathrm{PT}$, et al. The cytotoxic T cell proteome and its shaping by the kinase mTOR. Nat Immunol. (2016) 17:104-12. doi: 10.1038/ni.3314

27. Bailis W, Shyer JA, Zhao J, Canaveras JCG, Al Khazal FJ, Qu R, et al. Distinct modes of mitochondrial metabolism uncouple $\mathrm{T}$ cell differentiation and function. Nature. (2019) 571:403-7. doi: 10.1038/s41586-019-1311-3

28. Bengsch B, Johnson AL, Kurachi M, Odorizzi PM, Pauken KE, Attanasio J, et al. Bioenergetic insufficiencies due to metabolic alterations regulated by the inhibitory receptor PD-1 are an early driver of CD8 $(+)$ T cell exhaustion. Immunity. (2016) 45:358-73. doi: 10.1016/j.immuni.2016.07.008

29. Scharping NE, Menk AV, Moreci RS, Whetstone RD, Dadey RE, Watkins SC, et al. The tumor microenvironment represses $\mathrm{T}$ cell mitochondrial biogenesis to drive intratumoral $\mathrm{T}$ cell metabolic insufficiency and dysfunction. Immunity. (2016) 45:374-88. doi: 10.1016/j.immuni.2016.07.009

30. Schurich A, Pallett LJ, Jajbhay D, Wijngaarden J, Otano I, Gill US, et al. Distinct metabolic requirements of exhausted and functional virusspecific CD8 T cells in the same host. Cell Rep. (2016) 16:1243-52. doi: 10.1016/j.celrep.2016.06.078

31. Buck MD, O'Sullivan D, Klein Geltink RI, Curtis JD, Chang CH, Sanin $\mathrm{DE}$, et al. Mitochondrial dynamics controls $\mathrm{T}$ cell fate through metabolic programming. Cell. (2016) 166:63-76. doi: 10.1016/j.cell.2016.05.035

32. Hanahan D, Weinberg RA. Hallmarks of cancer: the next generation. Cell. (2011) 144:646-74. doi: 10.1016/j.cell.2011.02.013

33. Corbet C, Feron O. Cancer cell metabolism and mitochondria: nutrient plasticity for TCA cycle fueling. Biochim Biophys Acta Rev Cancer. (2017) 1868:7-15. doi: 10.1016/j.bbcan.2017.01.002 
34. Marbaniang C, Kma L. Dysregulation of glucose metabolism by oncogenes and tumor suppressors in cancer cells. Asian Pac J Cancer Prev. (2018) 19:2377-90. doi: 10.22034/APJCP.2018.19.9.2377

35. Charitou T, Srihari S, Lynn MA, Jarboui MA, Fasterius E, Moldovan M, et al. Transcriptional and metabolic rewiring of colorectal cancer cells expressing the oncogenic KRAS(G13D) mutation. Br J Cancer. (2019) 121:37-50. doi: 10.1038/s41416-019-0477-7

36. Liu J, Zhang C, Hu W, Feng Z. Tumor suppressor p53 and metabolism. J Mol Cell Biol. (2019) 11:284-92. doi: 10.1093/jmcb/mjy070

37. Mougiakakos D, Johansson CC, Kiessling R. Naturally occurring regulatory $\mathrm{T}$ cells show reduced sensitivity toward oxidative stress-induced cell death. Blood. (2009) 113:3542-5. doi: 10.1182/blood-2008-09-18 1040

38. Walton ZE, Patel CH, Brooks RC, Yu Y, Ibrahim-Hashim A, Riddle $\mathrm{M}$, et al. Acid suspends the circadian clock in hypoxia through inhibition of mTOR. Cell. (2018) 174:72-87 e32. doi: 10.1016/j.cell.2018. 05.009

39. Zheng Y, Delgoffe GM, Meyer CF, Chan W, Powell JD. Anergic $\mathrm{T}$ cells are metabolically anergic. J Immunol. (2009) 183:6095-101. doi: 10.4049/jimmunol.0803510

40. Battaglia M, Stabilini A, Roncarolo MG. Rapamycin selectively expands CD4+CD25+FoxP3+ regulatory T cells. Blood. (2005) 105:4743-8. doi: 10.1182/blood-2004-10-3932

41. Ren L, Zhang W, Han P, Zhang J, Zhu Y, Meng X, et al. Influenza A virus (H1N1) triggers a hypoxic response by stabilizing hypoxia-inducible factor-1alpha via inhibition of proteasome. Virology. (2019) 530:51-8. doi: 10.1016/j.virol.2019.02.010

42. Ohta A, Gorelik E, Prasad SJ, Ronchese F, Lukashev D, Wong MK, et al. A2A adenosine receptor protects tumors from antitumor T cells. Proc Natl Acad Sci USA. (2006) 103:13132-7. doi: 10.1073/pnas.0605251103

43. Najjar YG, Menk AV, Sander C, Rao U, Karunamurthy A, Bhatia $\mathrm{R}$, et al. Tumor cell oxidative metabolism as a barrier to PD-1 blockade immunotherapy in melanoma. JCI Insight. (2019) 4:124989. doi: 10.1172/jci.insight.124989

44. Marijt KA, Sluijter M, Blijleven L, Tolmeijer SH, Scheeren FA, van der Burg $\mathrm{SH}$, et al. Metabolic stress in cancer cells induces immune escape through a PI3K-dependent blockade of IFN $\gamma$ receptor signaling. J Immunother Cancer. (2019) 7:152. doi: 10.1186/s40425-019-0627-8

45. Brand A, Singer K, Koehl GE, Kolitzus M, Schoenhammer G, Thiel $A$, et al. LDHA-associated lactic acid production blunts tumor immunosurveillance by $\mathrm{T}$ and NK cells. Cell Metab. (2016) 24:657-71. doi: 10.1016/j.cmet.2016.08.011

46. Michalek RD, Gerriets VA, Jacobs SR, Macintyre AN, MacIver NJ, Mason EF, et al. Cutting edge: distinct glycolytic and lipid oxidative metabolic programs are essential for effector and regulatory CD4 $+\mathrm{T}$ cell subsets. J Immunol. (2011) 186:3299-303. doi: 10.4049/jimmunol.10 03613

47. Calcinotto A, Filipazzi P, Grioni M, Iero M, De Milito A, Ricupito A, et al. Modulation of microenvironment acidity reverses anergy in human and murine tumor-infiltrating T lymphocytes. Cancer Res. (2012) 72:2746-56. doi: 10.1158/0008-5472.CAN-11-1272

48. Hui S, Ghergurovich JM, Morscher RJ, Jang C, Teng X, Lu W, et al. Glucose feeds the TCA cycle via circulating lactate. Nature. (2017) 551:115-8. doi: $10.1038 /$ nature 24057

49. DeBerardinis RJ, Mancuso A, Daikhin E, Nissim I, Yudkoff M, Wehrli $\mathrm{S}$, et al. Beyond aerobic glycolysis: transformed cells can engage in glutamine metabolism that exceeds the requirement for protein and nucleotide synthesis. Proc Natl Acad Sci USA. (2007) 104:19345-50. doi: 10.1073/pnas.0709747104

50. Goveia J, Pircher A, Conradi LC, Kalucka J, Lagani V, Dewerchin M, et al. Meta-analysis of clinical metabolic profiling studies in cancer: challenges and opportunities. EMBO Mol Med. (2016) 8:1134-42. doi: 10.15252/emmm.201606798

51. Reznik E, Luna A, Aksoy BA, Liu EM, La K, Ostrovnaya I, et al. A landscape of metabolic variation across tumor types. Cell Syst. (2018) 6:301-13 e303. doi: 10.1016/j.cels.2017.12.014

52. Altman BJ, Stine ZE, Dang CV. From Krebs to clinic: glutamine metabolism to cancer therapy. Nat Rev Cancer. (2016) 16:749. doi: 10.1038/nrc.2016.114
53. Klysz D, Tai X, Robert PA, Craveiro M, Cretenet G, Oburoglu L, et al. Glutamine-dependent alpha-ketoglutarate production regulates the balance between T helper 1 cell and regulatory T cell generation. Sci Signal. (2015) 8:ra97. doi: 10.1126/scisignal.aab2610

54. Metzler B, Gfeller P, Guinet E. Restricting glutamine or glutamine-dependent purine and pyrimidine syntheses promotes human T cells with high FOXP3 expression and regulatory properties. J Immunol. (2016) 196:3618-30. doi: 10.4049/jimmunol.1501756

55. Fallarino F, Grohmann U, You S, McGrath BC, Cavener DR, Vacca C, et al. The combined effects of tryptophan starvation and tryptophan catabolites down-regulate $\mathrm{T}$ cell receptor zeta-chain and induce a regulatory phenotype in naive T cells. J Immunol. (2006) 176:6752-61. doi: 10.4049/jimmunol.176.11.6752

56. Mezrich JD, Fechner JH, Zhang X, Johnson BP, Burlingham WJ, Bradfield CA. An interaction between kynurenine and the aryl hydrocarbon receptor can generate regulatory T cells. J Immunol. (2010) 185:3190-8. doi: 10.4049/jimmunol.0903670

57. Komiya T, Huang $\mathrm{CH}$. Updates in the clinical development of epacadostat and other indoleamine 2,3-dioxygenase 1 inhibitors (IDO1) for human cancers. Front Oncol. (2018) 8:423. doi: 10.3389/fonc.2018.00423

58. Umansky V, Blattner C, Gebhardt C, Utikal J. The role of myeloid-derived suppressor cells (MDSC) in cancer progression. Vaccines. (2016) 4:E36. doi: $10.3390 /$ vaccines4040036

59. Kidani Y, Elsaesser H, Hock MB, Vergnes L, Williams KJ, Argus JP, et al. Sterol regulatory element-binding proteins are essential for the metabolic programming of effector $\mathrm{T}$ cells and adaptive immunity. Nat Immunol. (2013) 14:489-99. doi: 10.1038/ni.2570

60. Pearce EL, Walsh MC, Cejas PJ, Harms GM, Shen H, Wang LS, et al. Enhancing CD8 T-cell memory by modulating fatty acid metabolism. Nature. (2009) 460:103-7. doi: 10.1038/nature08097

61. van der Windt GJ, Everts B, Chang CH, Curtis JD, Freitas TC, Amiel E, et al. Mitochondrial respiratory capacity is a critical regulator of CD8+ T cell memory development. Immunity. (2012) 36:68-78. doi: 10.1016/j.immuni.2011.12.007

62. Currie E, Schulze A, Zechner R, Walther TC, Farese RV Jr. Cellular fatty acid metabolism and cancer. Cell Metab. (2013) 18:153-61. doi: 10.1016/j.cmet.2013.05.017

63. Purdy JG, Shenk T, Rabinowitz JD. Fatty acid elongase 7 catalyzes lipidome remodeling essential for human cytomegalovirus replication. Cell Rep. (2015) 10:1375-85. doi: 10.1016/j.celrep.2015.02.003

64. Lowey B, Hertz L, Chiu S, Valdez K, Li Q, Liang TJ. Hepatitis C virus infection induces hepatic expression of NF-kappaB-inducing kinase and lipogenesis by downregulating miR-122. MBio. (2019) 10:e01617-19. doi: 10.1128/mBio.01617-19

65. Chen J, Zhou Y, Zhuang Y, Qin T, Guo M, Jiang J, et al. The metabolic regulator small heterodimer partner contributes to the glucose and lipid homeostasis abnormalities induced by hepatitis $\mathrm{C}$ virus infection. Metabolism 2019:153954. doi: 10.1016/j.metabol.2019.153954

66. Dagogo-Jack I, Shaw AT. Tumour heterogeneity and resistance to cancer therapies. Nat Rev Clin Oncol. (2018) 15:81-94. doi: 10.1038/nrclinonc.2017.166

67. Paley MA, Kroy DC, Odorizzi PM, Johnnidis JB, Dolfi DV, Barnett $\mathrm{BE}$, et al. Progenitor and terminal subsets of CD8+ T cells cooperate to contain chronic viral infection. Science. (2012) 338:1220-5. doi: 10.1126/science.1229620

68. Utzschneider DT, Charmoy M, Chennupati V, Pousse L, Ferreira DP, Calderon-Copete $\mathrm{S}$, et al. T cell factor 1-expressing memory-like CD8(+) $\mathrm{T}$ cells sustain the immune response to chronic viral infections. Immunity. (2016) 45:415-27. doi: 10.1016/j.immuni.2016.07.021

69. Jameson SC, Masopust D. Understanding subset diversity in T cell memory. Immunity. (2018) 48:214-26. doi: 10.1016/j.immuni.2018.02.010

70. Maini MK, Schurich A. The molecular basis of the failed immune response in chronic HBV: therapeutic implications. J Hepatol. (2010) 52:616-9. doi: 10.1016/j.jhep.2009.12.017

71. Schurich A, Pallett LJ, Lubowiecki M, Singh HD, Gill US, Kennedy PT, et al. The third signal cytokine IL-12 rescues the anti-viral function of exhausted HBV-specific CD8 T cells. PLoS Pathog. (2013) 9:e1003208. doi: 10.1371 /journal.ppat.1003208 
72. Ahsan NA, Sampey GC, Lepene B, Akpamagbo Y, Barclay RA, Iordanskiy S, et al. Presence of viral RNA and proteins in exosomes from cellular clones resistant to rift valley fever virus infection. Front Microbiol. (2016) 7:139. doi: 10.3389/fmicb.2016.00139

73. Bukong TN, Momen-Heravi F, Kodys K, Bala S, Szabo G. Exosomes from hepatitis $\mathrm{C}$ infected patients transmit $\mathrm{HCV}$ infection and contain replication competent viral RNA in complex with Ago2-miR122HSP90. PLoS Pathog. (2014) 10:e1004424. doi: 10.1371/journal.ppat.10 04424

74. Chen L, Feng Z, Yue H, Bazdar D, Mbonye U, Zender C, et al. Exosomes derived from HIV-1-infected cells promote growth and progression of cancer via HIV TAR RNA. Nat Commun. (2018) 9:4585. doi: 10.1038/s41467-018-07006-2

75. Kalamvoki M, Du T, Roizman B. Cells infected with herpes simplex virus 1 export to uninfected cells exosomes containing STING, viral mRNAs, and microRNAs. Proc Natl Acad Sci USA. (2014) 111:E4991-6. doi: 10.1073/pnas.1419338111

76. Kapoor NR, Chadha R, Kumar S, Choedon T, Reddy VS, Kumar V. The $\mathrm{HBx}$ gene of hepatitis $\mathrm{B}$ virus can influence hepatic microenvironment via exosomes by transferring its mRNA and protein. Virus Res. (2017) 240:16674. doi: 10.1016/j.virusres.2017.08.009

77. Kim JH, Lee CH, Lee SW. Exosomal transmission of microRNA from HCV replicating cells stimulates transdifferentiation in hepatic stellate cells. $\mathrm{Mol}$ Ther Nucleic Acids. (2019) 14:483-97. doi: 10.1016/j.omtn.2019.01.006

78. Liu DX, Li PP, Guo JP, Li LL, Guo B, Jiao HB, et al. Exosomes derived from HBV-associated liver cancer promote chemoresistance by upregulating chaperone-mediated autophagy. Oncol Lett. (2019) 17:323-31. doi: 10.3892/ol.2018.9584

79. Otaguiri KK, Dos Santos DF, Slavov SN, Depieri LV, Palma PVB, Meirelles FV, et al. TAX-mRNA-carrying exosomes from human $\mathrm{T}$ cell lymphotropic virus type 1-infected cells can induce interferon-gamma production in vitro. AIDS Res Hum Retroviruses. (2018) 34. doi: 10.1089/aid.2018.0115

80. Ramakrishnaiah V, Thumann C, Fofana I, Habersetzer F, Pan Q, de Ruiter PE, et al. Exosome-mediated transmission of hepatitis $\mathrm{C}$ virus between human hepatoma Huh7.5 cells. Proc Natl Acad Sci USA. (2013) 110:13109-13. doi: $10.1073 /$ pnas. 1221899110

81. Sampey GC, Saifuddin M, Schwab A, Barclay R, Punya S, Chung MC, et al. Exosomes from HIV-1-infected cells stimulate production of proinflammatory cytokines through trans-activating response (TAR) RNA. J Biol Chem. (2016) 291:1251-66. doi: 10.1074/jbc.M115.662171

82. Temme S, Eis-Hubinger AM, McLellan AD, Koch N. The herpes simplex virus-1 encoded glycoprotein B diverts HLA-DR into the exosome pathway. J Immunol. (2010) 184:236-43. doi: 10.4049/jimmunol.0902192

83. Wang T, Fang L, Zhao F, Wang D, Xiao S. Exosomes mediate intercellular transmission of porcine reproductive and respiratory syndrome virus. J Virol. (2018) 92:e01734-17. doi: 10.1128/JVI.01734-17

84. Yang Y, Han Q, Hou Z, Zhang C, Tian Z, Zhang J. Exosomes mediate hepatitis B virus (HBV) transmission and NK-cell dysfunction. Cell Mol Immunol. (2017) 14:465-75. doi: 10.1038/cmi.2016.24

85. Kalluri R. The biology and function of exosomes in cancer. J Clin Invest. (2016) 126:1208-15. doi: 10.1172/JCI81135

86. Rajagopal C, Harikumar KB. The origin and functions of exosomes in cancer. Front Oncol. (2018) 8:66. doi: 10.3389/fonc.2018.00066

87. Tung KH, Ernstoff MS, Allen C, Shu S. A review of exosomes and their role in the tumor microenvironment and host-tumor "macroenvironment". J Immunol Sci. (2019) 3:4-8. doi: 10.29245/2578-3009/2019/1.1165

88. Lo AK, Dawson CW, Young LS, Lo KW. The role of metabolic reprogramming in gamma-herpesvirus-associated oncogenesis. Int J Cancer. (2017) 141:1512-21. doi: 10.1002/ijc.30795

89. Delgado T, Carroll PA, Punjabi AS, Margineantu D, Hockenbery DM, Lagunoff M. Induction of the Warburg effect by Kaposi's sarcoma herpesvirus is required for the maintenance of latently infected endothelial cells. Proc Natl Acad Sci USA. (2010) 107:10696-701. doi: $10.1073 /$ pnas. 1004882107

90. Delgado T, Sanchez EL, Camarda R, Lagunoff M. Global metabolic profiling of infection by an oncogenic virus: KSHV induces and requires lipogenesis for survival of latent infection. PLoS Pathog. (2012) 8:e1002866. doi: 10.1371/journal.ppat.1002866
91. Sanchez EL, Carroll PA, Thalhofer AB, Lagunoff M. Latent KSHV infected endothelial cells are glutamine addicted and require glutaminolysis for survival. PLoS Pathog. (2015) 11:e1005052. doi: 10.1371/journal.ppat.1005052

92. Sanchez EL, Pulliam TH, Dimaio TA, Thalhofer AB, Delgado T, Lagunoff M. Glycolysis, glutaminolysis, and fatty acid synthesis are required for distinct stages of Kaposi's sarcoma-associated herpesvirus lytic replication. J Virol. (2017) 91:e02237-16. doi: 10.1128/JVI.02237-16

93. Singh RK, Lang F, Pei Y, Jha HC, Robertson ES. Metabolic reprogramming of Kaposi's sarcoma associated herpes virus infected B-cells in hypoxia. PLoS Pathog. (2018) 14:e1007062. doi: 10.1371/journal.ppat.1007062

94. Yogev O, Lagos D, Enver T, Boshoff C. Kaposi's sarcoma herpesvirus microRNAs induce metabolic transformation of infected cells. PLoS Pathog. (2014) 10:e1004400. doi: 10.1371/journal.ppat.1004400

95. Chugh PE, Sin SH, Ozgur S, Henry DH, Menezes P, Griffith J, et al. Systemically circulating viral and tumorderived microRNAs in KSHV-associated malignancies. PLoS Pathog. (2013) 9:e1003484. doi: 10.1371/journal.ppat.10 03484

96. McNamara RP, Chugh PE, Bailey A, Costantini LM, Ma Z, Bigi $\mathrm{R}$, et al. Extracellular vesicles from Kaposi Sarcoma-associated herpesvirus lymphoma induce long-term endothelial cell reprogramming. PLoS Pathog. (2019) 15:e1007536. doi: 10.1371/journal.ppat.10 07536

97. Yogev O, Henderson S, Hayes MJ, Marelli SS, Ofir-Birin Y, RegevRudzki N, et al. Herpesviruses shape tumour microenvironment through exosomal transfer of viral microRNAs. PLoS Pathog. (2017) 13:e1006524. doi: 10.1371/journal.ppat.1006524

98. Piccaluga PP, Weber A, Ambrosio MR, Ahmed Y, Leoncini L. Epstein-Barr virus-induced metabolic rearrangements in human B-cell lymphomas. Front Microbiol. (2018) 9:1233. doi: 10.3389/fmicb.2018.01233

99. Zhang J, Jia L, Liu T, Yip YL, Tang WC, Lin W, et al. mTORC2-mediated PDHE1 $\alpha$ nuclear translocation links EBV-LMP1 reprogrammed glucose metabolism to cancer metastasis in nasopharyngeal carcinoma. Oncogene. (2019) 38:4669-84. doi: 10.1038/s41388-019-0749-y

100. Cai TT, Ye SB, Liu YN, He J, Chen QY, Mai HQ, et al. LMP1mediated glycolysis induces myeloid-derived suppressor cell expansion in nasopharyngeal carcinoma. PLoS Pathog. (2017) 13:e1006503. doi: 10.1371/journal.ppat.1006503

101. Marshall NA, Culligan DJ, Tighe J, Johnston PW, Barker RN, Vickers MA. The relationships between Epstein-Barr virus latent membrane protein 1 and regulatory T cells in Hodgkin's lymphoma. Exp Hematol. (2007) 35:596-604. doi: 10.1016/j.exphem.2007.01.030

102. Baglio SR, van Eijndhoven MA, Koppers-Lalic D, Berenguer J, Lougheed SM, Gibbs S, et al. Sensing of latent EBV infection through exosomal transfer of 5'pppRNA. Proc Natl Acad Sci USA. (2016) 113:E587-96. doi: 10.1073/pnas.1518130113

103. Hurwitz SN, Nkosi D, Conlon MM, York SB, Liu X, Tremblay DC, et al. CD63 regulates Epstein-Barr virus LMP1 exosomal packaging, enhancement of vesicle production, and noncanonical NF-kappaB signaling. J Virol. (2017) 91:e00251-16. doi: 10.1128/JVI.02251-16

104. Valle-Casuso JC, Angin M, Volant S, Passaes C, Monceaux V, Mikhailova A, et al. Cellular metabolism is a major determinant of HIV-1 reservoir seeding in CD4(+) T cells and offers an opportunity to tackle infection. Cell Metab. (2019) 29:611-26 e615. doi: 10.1016/j.cmet.2018.11.015

105. Clerc I, Abba Moussa D, Vahlas Z, Tardito S, Oburoglu L, Hope TJ, et al. Entry of glucose- and glutamine-derived carbons into the citric acid cycle supports early steps of HIV-1 infection in CD4 T cells. Nature Metabolism. (2019) 1:717-30. doi: 10.1038/s42255-019-0084-1

106. Pearce EL, Pearce EJ. Metabolic pathways in immune cell activation and quiescence. Immunity. (2013) 38:633-43. doi: 10.1016/j.immuni.2013. 04.005

107. Zhang YX, Zhao YY, Shen J, Sun X, Liu Y, Liu H, et al. Nanoenabled modulation of acidic tumor microenvironment reverses anergy of infiltrating T cells and potentiates anti-PD-1 therapy. Nano Lett. (2019) 19:2774-83. doi: 10.1021/acs.nanolett.8b04296

108. Daneshmandi S, Wegiel B, Seth P. Blockade of lactate dehydrogenaseA (LDH-A) improves efficacy of anti-programmed cell death-1 (PD-1) 
therapy in melanoma. Cancers. (2019) 11:E450. doi: 10.3390/cancers 110 40450

109. Seth P, Csizmadia E, Hedblom A, Vuerich M, Xie H, Li M, et al. Deletion of lactate dehydrogenase-A in myeloid cells triggers antitumor immunity. Cancer Res. (2017) 77:3632-43. doi: 10.1158/0008-5472.CAN-16-2938

110. Ligtenberg MA, Mougiakakos D, Mukhopadhyay M, Witt K, Lladser A, Chmielewski $M$, et al. Coexpressed catalase protects chimeric antigen receptor-redirected $\mathrm{T}$ cells as well as bystander cells from oxidative stress-induced loss of antitumor activity. J Immunol. (2016) 196:759-66. doi: 10.4049/jimmunol.1401710

111. Qiu J, Villa M, Sanin DE, Buck MD, O'Sullivan D, Ching R, et al. Acetate promotes T cell effector function during glucose restriction. Cell Rep. (2019) 27:2063-74 e2065. doi: 10.1016/j.celrep.2019.04.022

112. Yun CW, Lee SH. The roles of autophagy in cancer. Int J Mol Sci. (2018) 19:E3466. doi: 10.3390/ijms19113466

113. Choi Y, Bowman JW, Jung JU. Autophagy during viral infection - a double-edged sword. Nat Rev Microbiol. (2018) 16:341-54. doi: 10.1038/s41579-018-0003-6
114. Rosato PC, Wijeyesinghe S, Stolley JM, Nelson CE, Davis RL, Manlove LS, et al. Virus-specific memory $\mathrm{T}$ cells populate tumors and can be repurposed for tumor immunotherapy. Nat Commun. (2019) 10:567. doi: 10.1038/s41467-019-08534-1

115. Farrell PJ. Epstein-Barr virus and cancer. Annu Rev Pathol. (2019) 14:29-53. doi: 10.1146/annurev-pathmechdis-012418-013023

Conflict of Interest: The authors declare that the research was conducted in the absence of any commercial or financial relationships that could be construed as a potential conflict of interest.

Copyright (C) 2019 Magalhaes, Yogev, Mattsson and Schurich. This is an open-access article distributed under the terms of the Creative Commons Attribution License (CC $B Y)$. The use, distribution or reproduction in other forums is permitted, provided the original author(s) and the copyright owner(s) are credited and that the original publication in this journal is cited, in accordance with accepted academic practice. No use, distribution or reproduction is permitted which does not comply with these terms. 